\title{
Investigation of Solar Chimney System and the Effect of Thermal Storage Capacity on the System Performance Part I: Experimental Investigation
}

\author{
Rabia AL. Galia ${ }^{1}$, Bashir H. Arebi ${ }^{2}$, and Essaied M. Shuia ${ }^{3}$ \\ ${ }^{1}$ Faculty of Natural Resources- Al. Ajaylat-Libya' \\ ${ }^{2}$ Faculty of Engineering, Tripoli University, Tripoli-Libya \\ ${ }^{3}$ Faculty of Engineering, Sabratha University, Sabratha-Libya \\ e-mail: ${ }^{1}$ rab_5426@yahoo.com; ${ }^{2}$ arebi_bashir@yahoo.co.uk; ${ }^{3}$ essaied_shuia@yahoo.com
}

\begin{abstract}
The performance and the thermal behavior of the solar chimney were investigated experimentally. The experimental data were collected from small pilot solar chimney which was designed and constructed at Sabratha Faculty of Engineering-Libya. Solar chimneys need solar radiation in order to work, thus, to have more stable condition, solar energy should be stored during the day and released back during the night. In order to investigate the temperature field during daylight and hours of darkness, the data were collected for a period of 24 hours for several days of months, May and June 2014. The investigation also include the effect of thermal storage on the temperature field. The solar chimney system contains two main components; the solar collector and the solar chimney. The solar collector roof has a circular area of $126 \mathrm{~m}^{2}$. A PVC pipe 0.2 $\mathrm{m}$ in diameter and $9 \mathrm{~m}$ in height was used as a chimney. Water containers were put as thermal blocks to study the effect of thermal storage on the performance of solar chimney. The measurements included the intensity of solar radiation inside/outside the collector, temperature and velocity of heated air at the entrance of the chimney, temperature and speed of wind outside the collector, temperature of the ground inside the collector and temperature measurements of air at particular points at different levels throughout the collector. Solar irradiance was found to affect the chimney temperature and subsequently chimney air velocity. The temperature difference between the hot air at chimney entrance and the ambient reached about $45^{\circ} \mathrm{C}$, which generates the driving force of airflow in the chimney. The hot air velocity in the chimney can reach $3.6 \mathrm{~m} / \mathrm{s}$ $(\approx 0.118 \mathrm{~kg} / \mathrm{sec}$ ). Wind speed was found to have a small influence on the performance of the solar chimney. The results indicate that the solar chimney system can operate in northwestern Libya. If this type of system is used on a large scale it can trap solar radiation and store a sufficient amount of heat through the use of additional heat storage such as water, which raises the air temperature in the collector after sunset to a sufficient value capable of generating air flow for a long time to run turbines to produce electricity during the day and after sunset especially during the summer time.
\end{abstract}




\section{دراسة نظام المدخنة الشمسية وتاثير سعة التخزين الحراري على أداي النظام

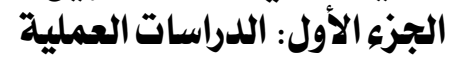

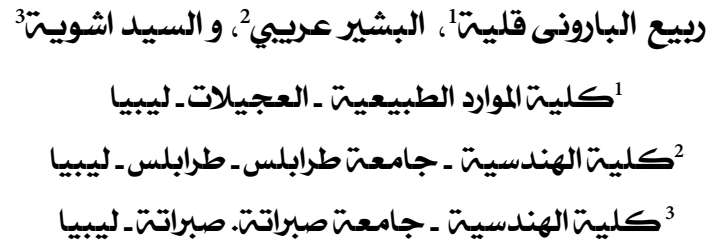

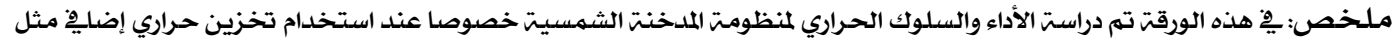

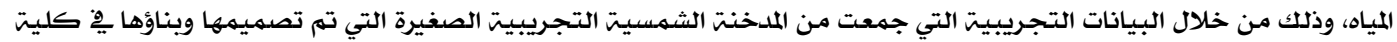

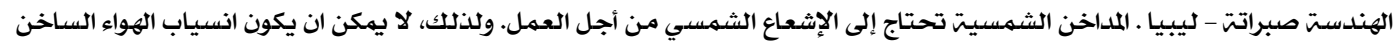

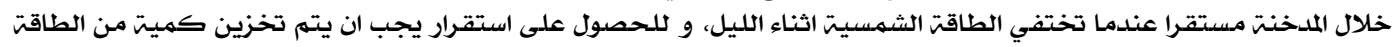

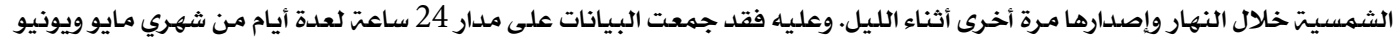

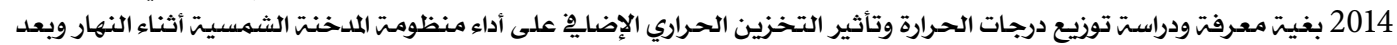

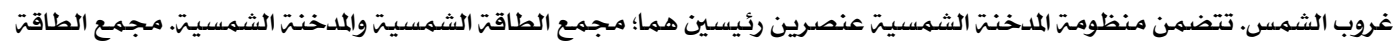

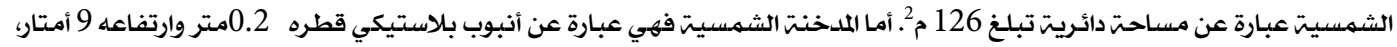

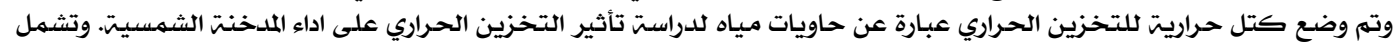

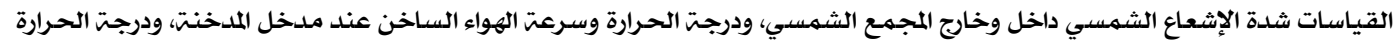

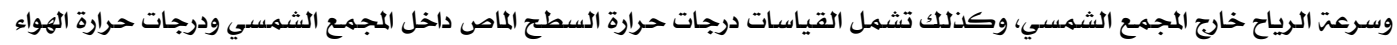

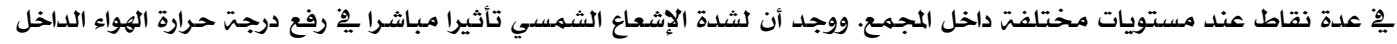

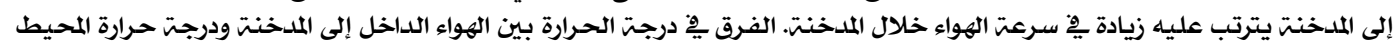

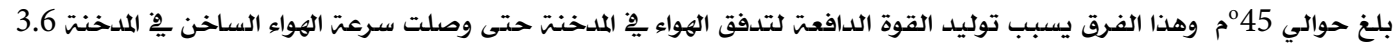

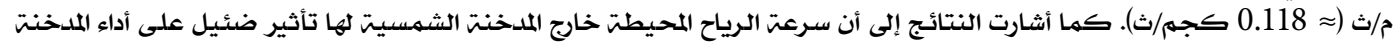

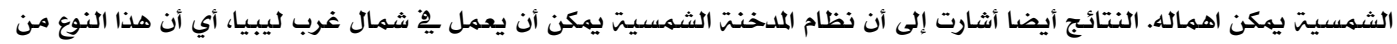

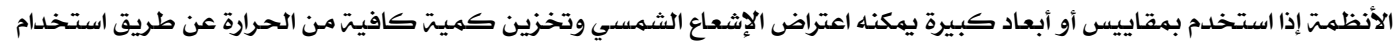

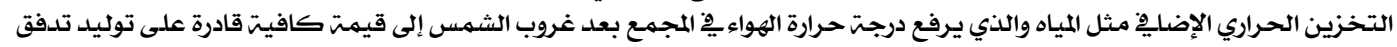

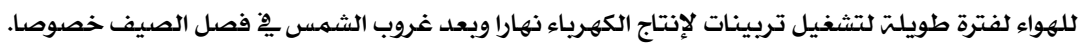

Keywords: Solar chimney; buoyancy effect; thermal storage; renewable energy.

\section{INTRODUCTION}

Solar chimney power plant (SCPP) is a relatively novel technology for electricity production from solar energy. The SCPP consists of a greenhouse roof collector and updraft chimney located at the center of the greenhouse roof collector. The greenhouse roof collector is usually made of plastic sheet or glass plate which traps solar energy and elevates the air temperature. The chimney is used to direct and vent the hot air through the wind turbine. The wind turbine is used to convert the air kinetic energy into mechanical work. No full scale solar chimney power plant has been operated to date, however many proposals have been investigated in different parts of the world. The feasibility of SCPP was evaluated by different experimental studies. The first outstanding action for the solar chimney power plant (SCPP) development was the prototype erection in 1982 in Manzanares, $150 \mathrm{~km}$ south of Madrid, Spain $[1,2,3]$. The chimney height was $195 \mathrm{~m}$ and its diameter was $10 \mathrm{~m}$. The collector area was 46,000 $\mathrm{m}^{2}$. Regardless of its dimensions this prototype was considered as a small-scale experimental model as the model was not intended for power generation, the peak power output was about $50 \mathrm{~kW}$. A pilot experimental solar chimney was built in Adıyaman 
University by Buğutekin [4]. A collector of $27 \mathrm{~m}$ diameter and a chimney of $17 \mathrm{~m}$ height were used to investigate the effect of environmental temperature, chimney height, the collector diameter, the value of solar radiation, etc. on the performance of solar chimney system. It was found that solar radiation and environmental temperature had a considerable impact on the system and temperature difference between the environment temperature and the air temperature inside the chimney $\left(21-26^{\circ} \mathrm{C}\right)$. Moreover, it was found that the environmental air velocity has no effect on the system. Chaichan M. \& Kazem H. [5] investigated the effects of the heat storage capacity of ground materials on solar chimney's air temperatures, in the region of Baghdad city- Iraq. The results showed that the best chimney efficiency attained was $49.7 \%$ for pebbles base and the highest collected air temperature reached was $49^{\circ} \mathrm{C}$ when using the black pebbles basement. Also, the maximum basement temperature measured was $59^{\circ} \mathrm{C}$ for black pebbles. Pretorius [6] studied the temperature distributions in the ground of the collector and found that the ground plays an important role in the energy consumption. Pretorius compared the power outputs of five different ground types: sandstone, granite, limestone, sand and wet soil. They found that the SCPPs employing wet soil and sand have the lowest and highest power outputs respectively.

\section{DESCRIPTION OF THE PILOT EXPERIMENTAL SOLAR CHIMNEY}

The pilot experimental solar chimney facility was constructed in Sabratha University- Libya, in fall 2013 [7]. This pilot experiment was developed and used in this study. In order to investigate the effect of thermal storage on the performance of the solar chimney, the collector was provided with additional thermal storages; water containers were laid down side by side on the collector floor. A schematic diagram of the system is shown in Figure 1. A number of photographs of the pilot experimental solar chimney are shown in Figure 2.

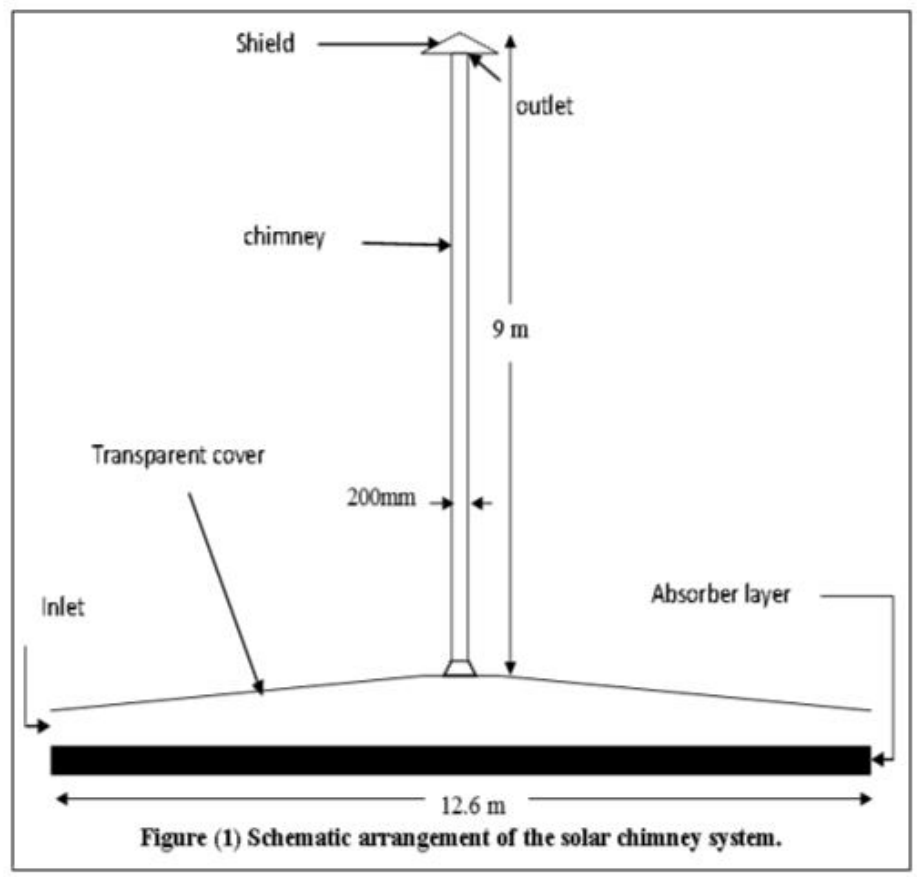

The tested solar chimney prototype contains

two main components; solar collector and chimney. 


\subsection{Solar collector}

The solar collector has a circular shape with a floor of $126 \mathrm{~m}^{2}$ area. This area is covered with transparent plastic of $0.2 \mathrm{~mm}$ thickness. The plastic cover is raised by a steel framework from height of $0.3 \mathrm{~m}$ at the outer radius to $0.8 \mathrm{~m}$ at the center of the collector just under the chimney entrance. In order to allow air flow into the system, several holes were made around the outer edge of the collector. as an insulator. A plastic film was placed between the two layers to allow changing the absorber layer whenever needed. The layers of crushed sandstones and sawdust wood were spread evenly over the floor; the thermo-physical properties of the materials used in the solar chimney system components are shown in Table 1. The central base of the solar chimney is supported by a concrete stand to ensure the stability of the system.

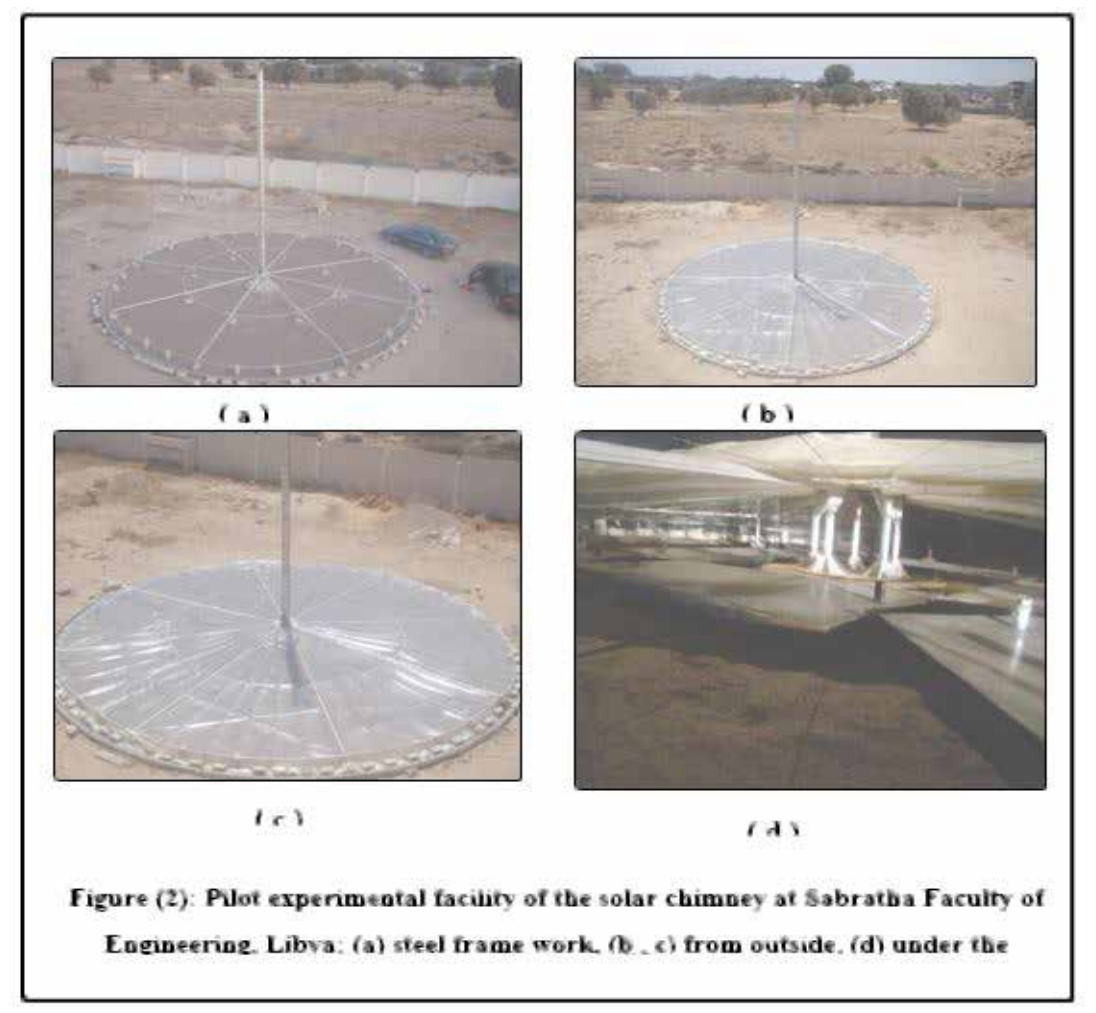

A central base is attached to eight hinges which are distributed uniformly around the base. These hinges were assembled with a rectangular structural tube $\left(0.5 \mathrm{~m}^{*} 0.35 \mathrm{~m}^{*} 6 \mathrm{~m}\right.$, with $2 \mathrm{~mm}$ thick). The rectangular tubes were supported by two radial tubes to avoid the deflection on a steel framework. The steel framework is shown in figure 2- a. The floor of the collector was made of two layers, the upper layer is about $6 \mathrm{~cm}$ thick of fine crushed black sandstones working as an absorber, and the second layer is a fine wood (sawdust wood) working

\subsection{Chimney}

The chimney itself is the actual thermal engine of the solar chimney plant. It is a pressure tube with low friction loss. The updraft of the air heated in the collector is approximately proportional to the air temperature rise $(\Delta \mathrm{T})$ in the collector and to the height of the chimney. The chimney was constructed from PVC pipe with an inside diameter of $192 \mathrm{~mm}$ and a height of $9 \mathrm{~m}$. This pipe is covered with glass wool blanket $(10 \mathrm{~mm}$ thick and thermal conductivity $\mathrm{k}=0.05 \mathrm{~W} / \mathrm{m} \mathrm{K}$ ) which works as a 
thermal insulator to reduce heat losses from the chimney wall. The thermal insulator is covered with aluminum foil to prevent insulation from wetness; also the chimney outlet is covered with a cap to avoid rain infiltration into the chimney. The chimney is connected to a conical nozzle which works as a base for the chimney. To sustain the chimney, two coupling rings were fixed around it.

Table (1). Properties of the materials used in the solar chimney system [8].

\begin{tabular}{|c|c|c|c|c|c|c|}
\hline $\begin{array}{c}\text { Properties } \\
\text { component }\end{array}$ & $\begin{array}{c}\text { Density } \\
\left(\mathrm{kg} / \mathrm{m}^{3}\right)\end{array}$ & $\begin{array}{c}\text { Thermal } \\
\text { conductivity } \\
(\mathrm{W} / \mathrm{m} . \mathrm{K})\end{array}$ & $\begin{array}{c}\text { Specific heat } \\
(\mathrm{kJ} / \mathrm{kg} . \mathrm{K})\end{array}$ & absorptivity & transmissivity & emissivity \\
\hline $\begin{array}{c}\text { Insulator } \\
\text { (sawdust wood) }\end{array}$ & 150 & 0.06 & 1.9 & - & - & - \\
\hline $\begin{array}{c}\text { absorber } \\
\text { (sandstone) }\end{array}$ & 2160 & 1.83 & 0.71 & 0.9 & - & 0.9 \\
\hline $\begin{array}{c}\text { Collector roof } \\
\text { (Polyethylene) }\end{array}$ & 918 & 0.33 & 2.3 & 0.0 & 0.89 & 0.15 \\
\hline
\end{tabular}

\subsection{Thermal storage tanks}

Thermal storage system contributes in the regulation of the air flow through the chimney; hence an additional thermal storage capacity is desired. Using water-filled black containers as heat storage underneath the collector roof is an effective method for storing heat; since the specific heat of water $\left(4.2 \mathrm{~kJ} / \mathrm{kg} .{ }^{\circ} \mathrm{K}\right)$ is much higher than that of sandstone $\left(0.69-0.85 \mathrm{~kJ} / \mathrm{kg} .{ }^{\circ} \mathrm{K}\right)$. The water inside the containers stores part of the solar heat and releases it during the night when the air in the collector cools down, this enables the airflow through the chimney to go further when solar energy vanishes. Eight water containers were made of steel sheets of $2 \mathrm{~mm}$ thick and the dimensions of single container are $1.9 \times 0.9 \times 0.1$ meters. The water containers are laid down side by side on the floor under the collector,(see Figure 3). The containers are filled with water once and remain closed so that no evaporation can take place. Usually the volume of water in the container is selected to correspond to a water layer with a depth of 5 to $20 \mathrm{~cm}$ depending on the desired power output characteristics [9]; in this study, the depth of $10 \mathrm{~cm}$ was chosen.

\subsection{Measuring instruments}

The experiments were carried out during the summer of 2014. The temperature distribution throughout the solar chimney, solar radiation, air velocity through the chimney, wind speed and the ambient temperature were measured at one hour interval for twenty-two hours daily.

The instrumentations used in the experiment include the following; 1) a pyranometer with datalogger was used to measure the solar radiation, the instrument has a range of 0 to $4000 \mathrm{~W} / \mathrm{m}^{2}$ with accuracy of $\pm 0.1 \%$. 2) two anemometers type (AR836) were used to measure the air velocity at the chimney entrance and the wind speed outside the collector, the instruments have a range of 0 to $25 \mathrm{~m} / \mathrm{s}$ with an accuracy of \pm 0.05 $\mathrm{m} / \mathrm{s}$. 3) forty thermocouples were used to measure the temperature distribution throughout the system. All the thermocouples are Ni-cv/Ni-Al type $\mathrm{K}$, the thermocouples were connected to digital thermometers (DT-612). Together with the digital thermometers the thermocouples were calibrated with an accuracy of $\pm 0.2{ }^{\circ} \mathrm{C}$. Because the temperature measurements were taken directly from the digital thermometer, the uncertainty of the temperature measurement is assumed to be defined by the calibration accuracy which is equal to \pm 0.2 ${ }^{\circ} \mathrm{C}$. Schematic diagrams of the measuring positions are shown in Figure 4. The collector is divided into 
ten sections; each section consists of four measuring nodes distributed horizontally as follows; 1) ten nodes under the insulation layer. 2) ten nodes at the absorber layer. 3) ten nodes in the middle of the air gap. 4) ten nodes under a transparent cover.
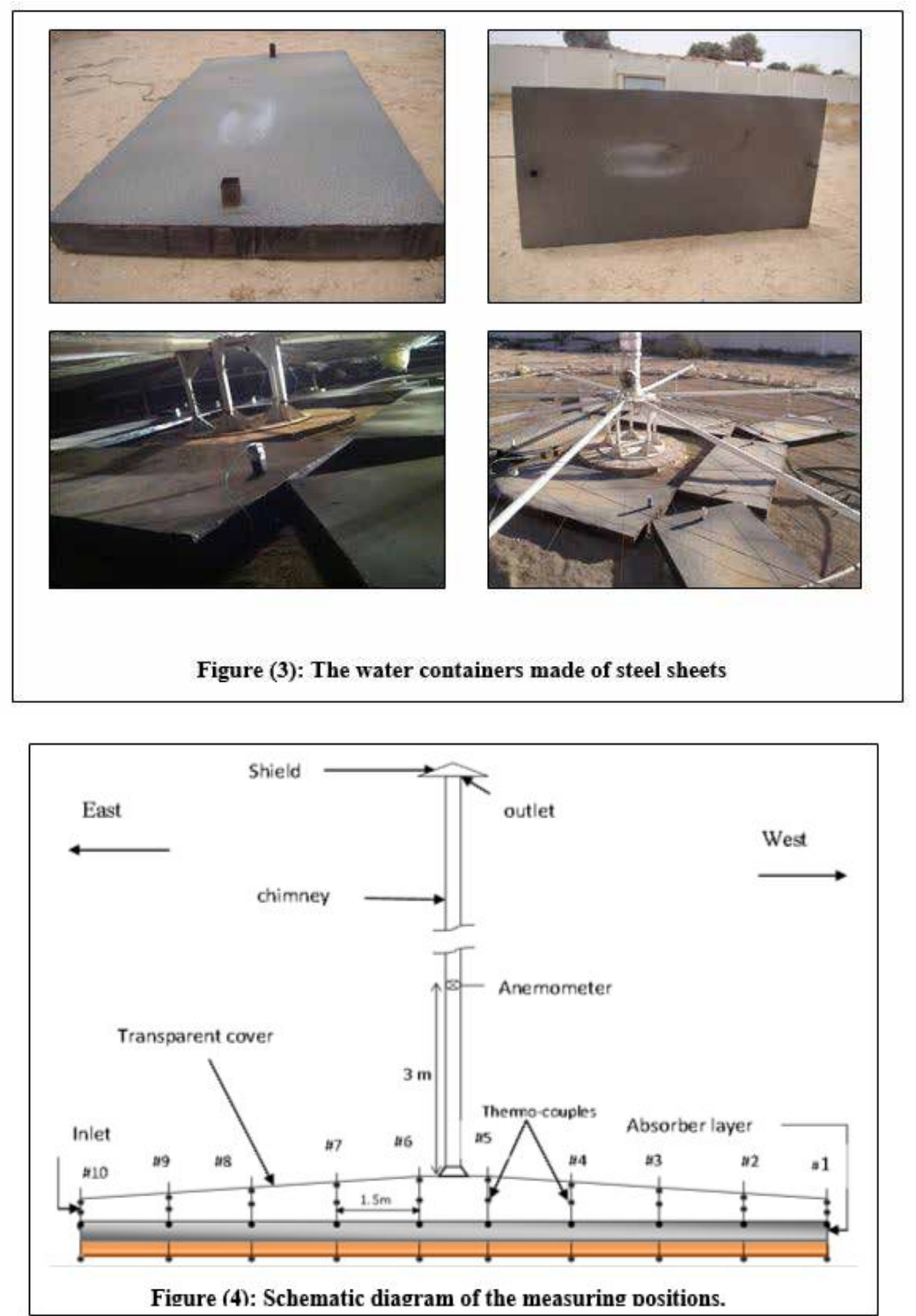

\section{3- EXPERIMENTAL RESULTS AND DISCUSSION}

Experimental data were recorded for various days in order to investigate the thermal behavior and the performance of the solar chimney in two cases; a) the case when the solar collector incorporating additional thermal energy storage; b) the case when 

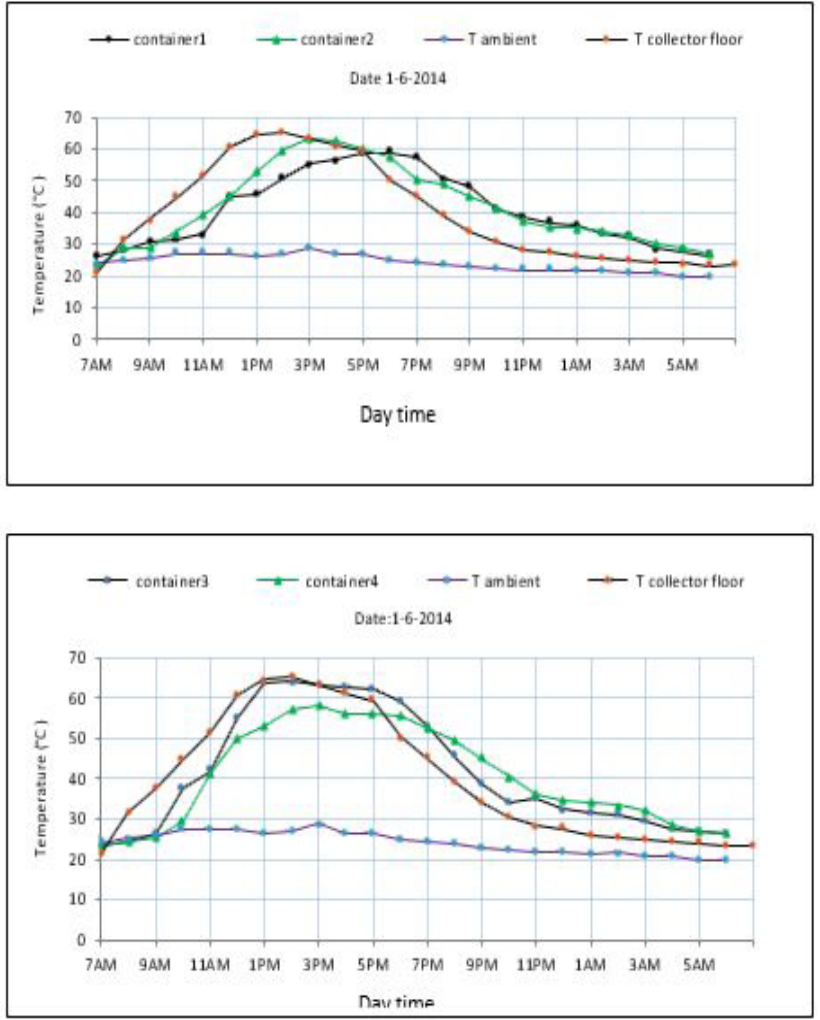

Figure (5): Temperatures at collector floor and that of water containers during the day (experimental results with water containers as thermal storage)

the solar collector was without additional thermal storage. The tests covered the following; 1) solar radiation intensity during day time; 2) temperature distribution at particular points inside the collector and at chimney inlet; 3) velocity through the chimney. 4) wind speed and ambient temperature. The data from the tests are illustrated in Figures 5 to 15 .

\subsection{Thermal storage}

Figure 5 presents temperatures of the collector floor (sandstone) and the water containers as additional thermal storage during heat charging and discharging periods. The ground under the collector roof is not only acting as a storage medium, but also can even heat up the air for a significant time after sunset. As shown, during the charging period, the surface temperature depends on the applied solar heat flux and the specific heat of the storage; the higher the heat flux is, the higher the absorber temperatures become. Similarly, the higher heat capacity values lead to an increase in the heat storage capacity of the absorber material. The water containers recorded lower temperatures during heat charging than that of collector floor because the water stores more heat than collector floor, since the specific heat of water $\left(4.2 \mathrm{~kJ} / \mathrm{kg}\right.$. $\left.{ }^{\circ} \mathrm{K}\right)$ is much higher than that of sandstone $\left(0.71 \mathrm{~kJ} / \mathrm{kg}\right.$. $\left.{ }^{\circ} \mathrm{K}\right)$. During heat discharging periods after sunset, the heat stored during the day is released to the air inside the collector after sunset. Figure 5 shows that after sunset, the water containers remain with higher 


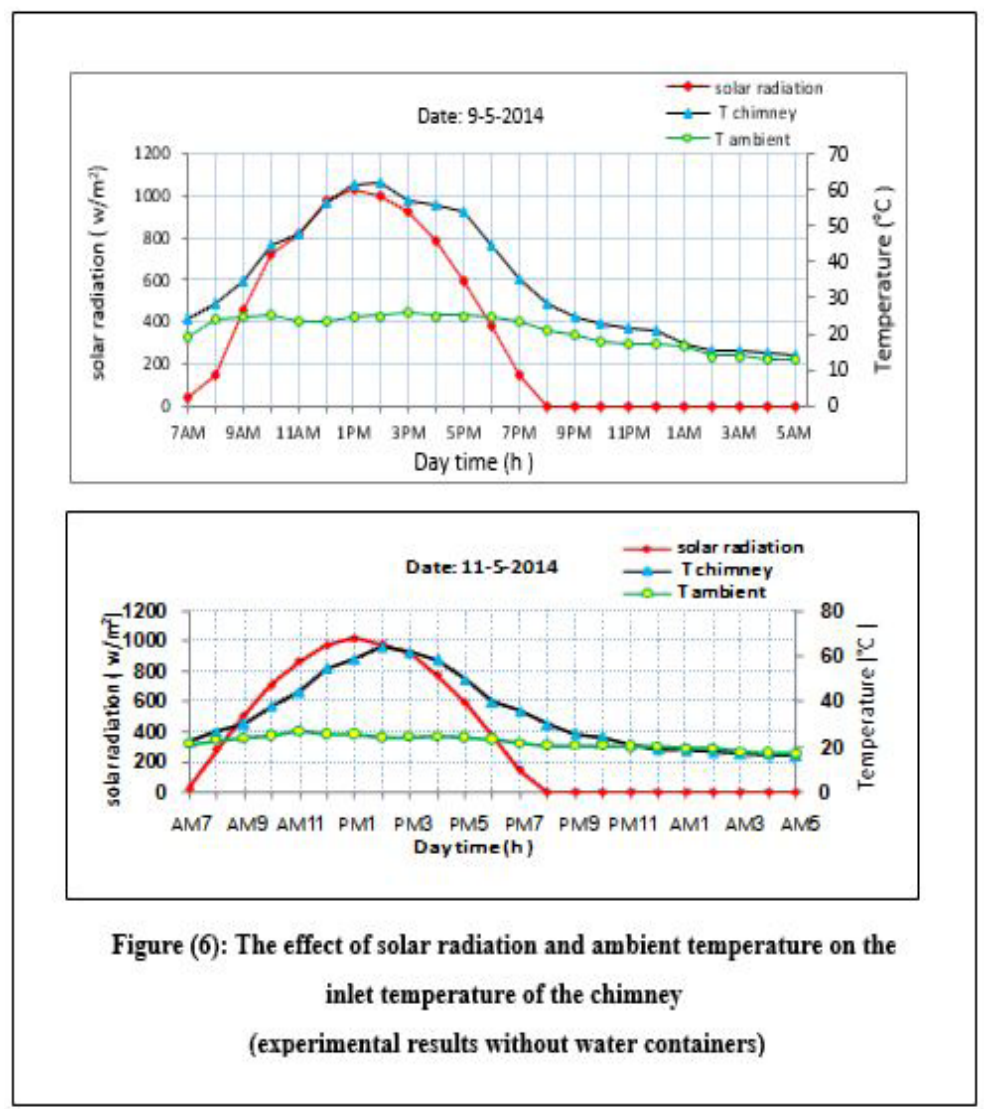

temperatures than that of the collector floor; this is attributed to the fact that the water stored more heat than that stored by soil during charging time.

\subsection{Solar chimney system.}

The results present the solar radiation intensity during day time, temperature distribution at particular points inside the collector and at chimney inlet, velocity through the chimney, wind speed and ambient temperature. The data from the tests are illustrated in Figures 6 to 15. Figures $6 \& 7$ show that, as the solar intensity increases the heat absorption by collector floor is increased, which in sequence increases the air temperature inside the collector. Using additional water thermal storages absorb more energy than that of natural thermal storage (sandstone), this energy is released into the collector at night. Thus, using additional water thermal storages reduces the air temperatures and air velocities during the daytime to values lesser than that in the case of natural thermal storage and vice versa; this helps in reducing the differences in air velocities between daytime and nighttime. The air temperature at collector had its maximum value of about $64{ }^{\circ} \mathrm{C}$ at 14:00 on May the $11^{\text {th }}, 2014$. The air inside the chimney reached its maximum temperature of about $64^{\circ} \mathrm{C}$ just after noontime. However, when an additional storage was added, the air inside the chimney reached a maximum temperature of about $63{ }^{\circ} \mathrm{C}$ just after noontime.

Figures $8 \& 9$ show the variation of air velocity inside the chimney versus the solar radiation. The Figures show that the increase in the intensity of solar radiation leads to an increase in the air temperature inside the collector; as a result, the air expands and increases its speed towards the 

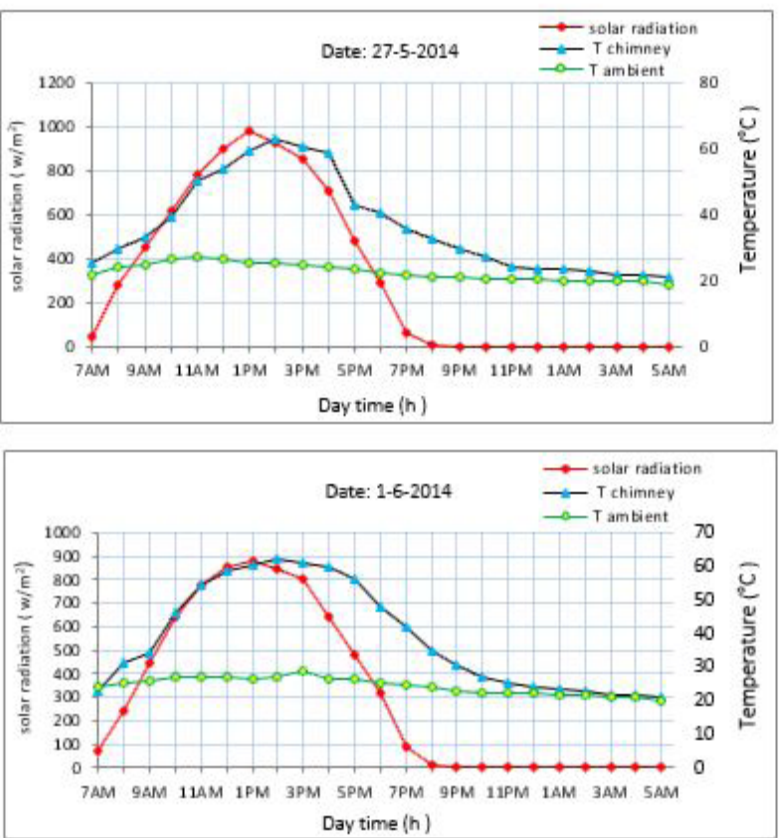

Figure (7): The effect of solar radiation and ambient temperature on the inlet temperature of the chimney

(experimental results with water containers as additional thermal storage)

chimney. In case of no additional storage added, the air inside the chimney reaches its maximum velocity of about $3.6 \mathrm{~m} / \mathrm{s}$. However, in the case of an additional storage is added, the air inside the chimney reaches its maximum velocity of about $3.3 \mathrm{~m} / \mathrm{s}$ after noon. From Figures $8 \& 9$, it can be noticed that the maximum velocity occurred at the corresponding maximum temperature of the absorber just after noon. Also Figures 8 \& 9 show that the heated air continues to flow into the solar chimney after sunset; this is because the thermal storage of the absorber continues to provide heat to the air even after sunset. The absorber with high thermal capacity is important for the absorption of more heat during the day and releasing it during the night. This allows continuous flow of air through the chimney at night and thus electricity can be produced even after sunset. Figures $8 \& 9$ indicate that any variation in the wind speed outside the solar collector leads to a small change in the air velocity inside the solar chimney; therefore the effect of the wind speed on the performance of the solar chimney system can be neglected, under the conditions of this experiment.

The temperature distribution in the middle of the solar collector was measured and presented in Figures $10 \& 11$. The figures show that ground temperature under the absorber during the day stayed nearly constant; this is due to very small heat loss to the ground. In the early morning hours, the absorber temperature is lower than the air temperature inside the collector, this leads to heat transfer from the air to the absorber; while in the midday and in the evening the temperature of the absorber is greater than the air temperature even after sunset; this is due to the thermal storage by the floor of the solar collector (absorber) which continues to provide heat to the air even after sunset. 

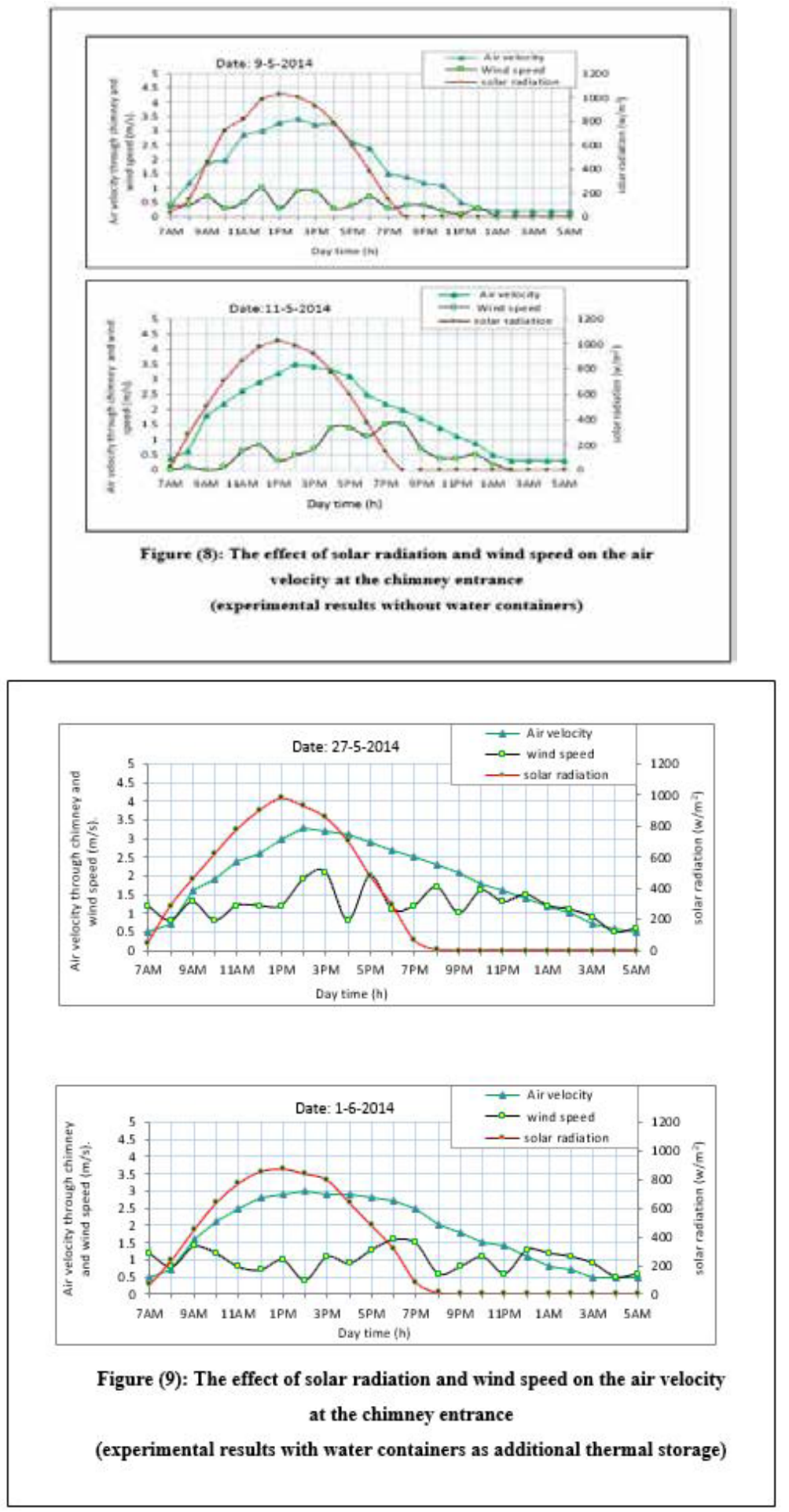


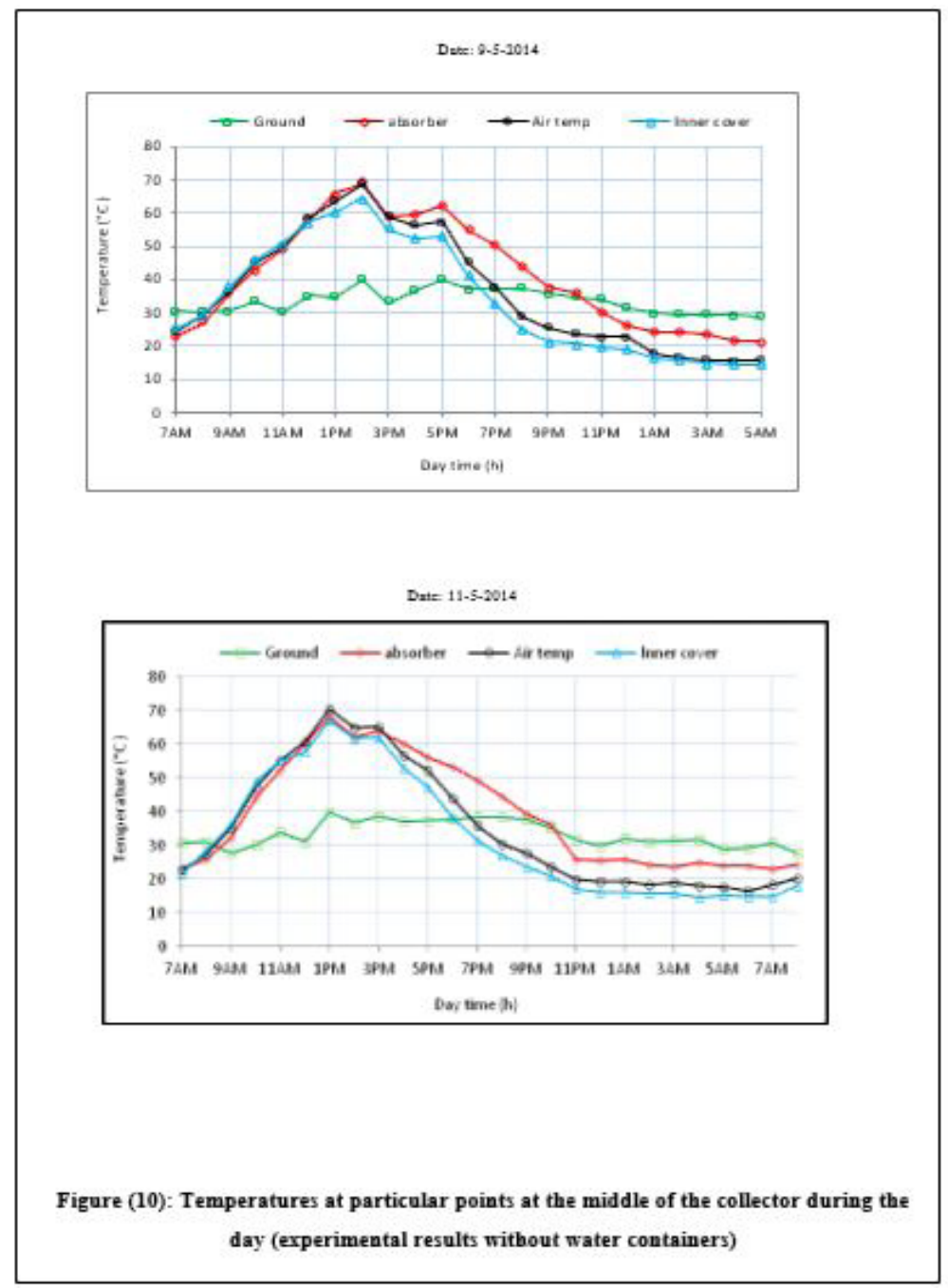

As shown in the schematic diagram of Figure 4, the collector is divided into ten sections; one of the sections consists of measuring nodes distributed in ten nodes in the middle of the air gap. Figures 12 \& 13 show the air temperature distribution at different sections throughout the collector. The minimum values of the temperatures were recorded at the morning and the maximum values were gained at noon when the solar irradiance reached its maximum value. Figures 12 \& 13 also indicate that maximum values of air temperatures occurred in the middle of the collector at the entrance of the chimney.

\subsection{The effect of using additional thermal storage on the system performance}

Figures $14 \& 15$ present experimental comparison between the solar chimney system behavior in two cases; (1) when the solar chimney system is not provided with water container as additional thermal storage; (2) when water container is used as an additional thermal storage in the solar chimney system.

Two days with similar weather conditions (see figure 14) were chosen to demonstrate the effect of using additional thermal storage on the behavior of the solar chimney system. 


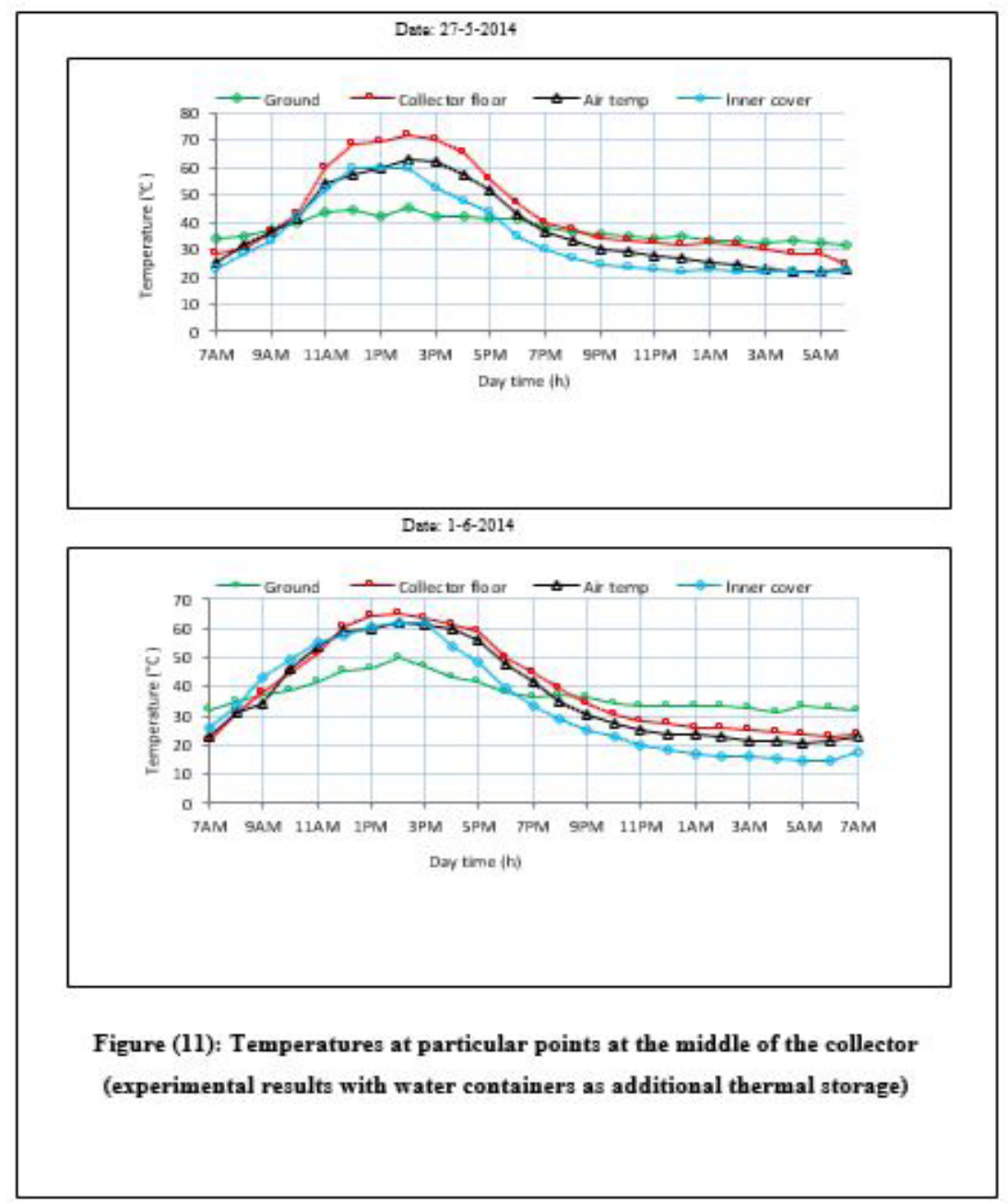

Figure 15 shows the temperatures and velocities of the air at the chimney entrance for the two cases mentioned above. During the daylight, when the solar radiation intensity is high, the air temperatures and velocities of casel are higher than that of case 2; this is because of high capacity of the water for storing heat than that of sandstone which leads to lower temperatures of water containers than that of collector floor. Later after sunset the water containers release the heat which was previously stored during the daylight. The heat transfers to the air and elevates the air temperatures and velocities for longer time after sunset.

Figure 15 shows the additional thermal storage (water containers) managed to heat up the air inside the solar collector for several hours (about 8 hours) after sunset. On the other hand, in case the water container is not provided to the system, the heating lasted only about four hours after sunset. The amount of energy stored is dependent on the mass of the thermal storage, the specific heat capacity and the rise in its temperature. Despite the limited collector size and limited additional thermal storages used in the experiment, this study provides evidence that using water (or any substance with high specific heat) as thermal storage improves the average air velocities through the solar chimney and gives the opportunity to operate the solar chimney longer after sunset. Also 


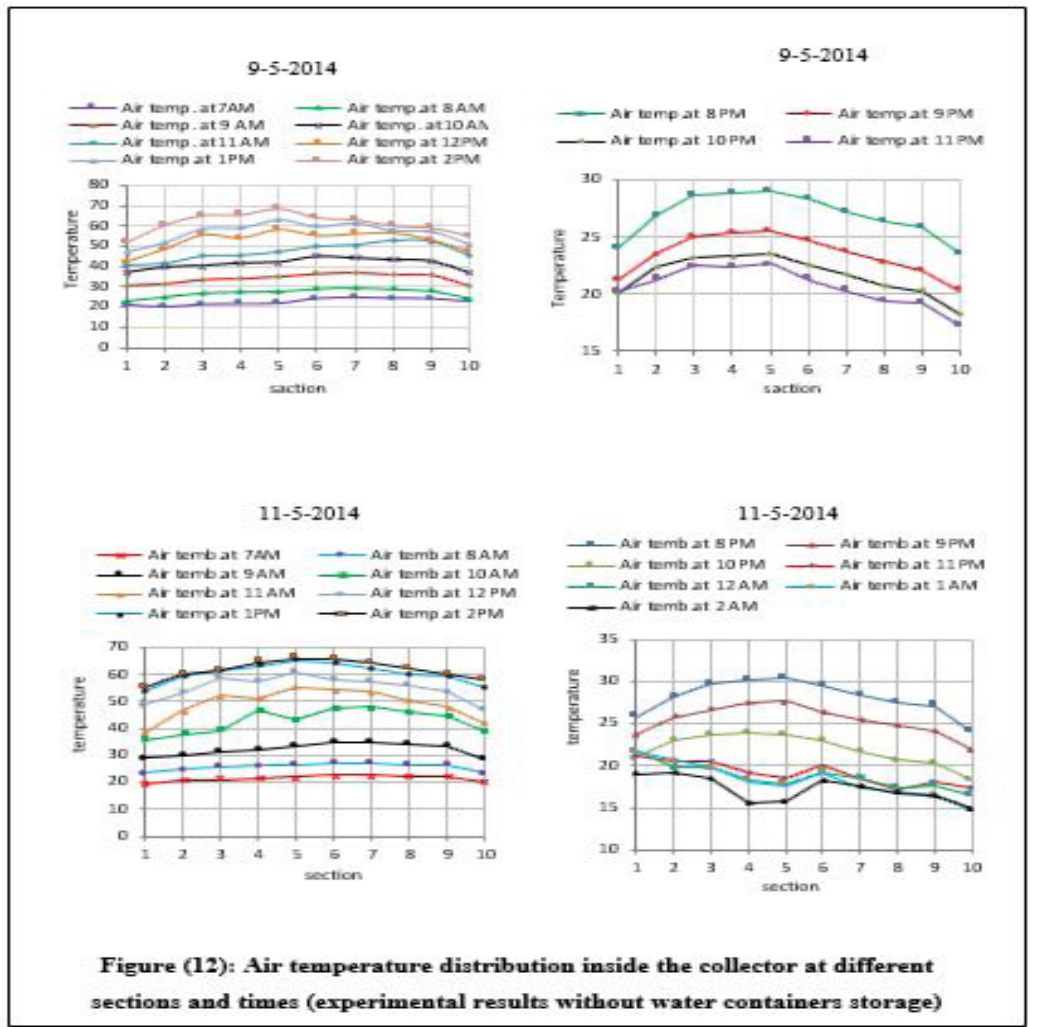
sections and times (experimental results without water containers storage)

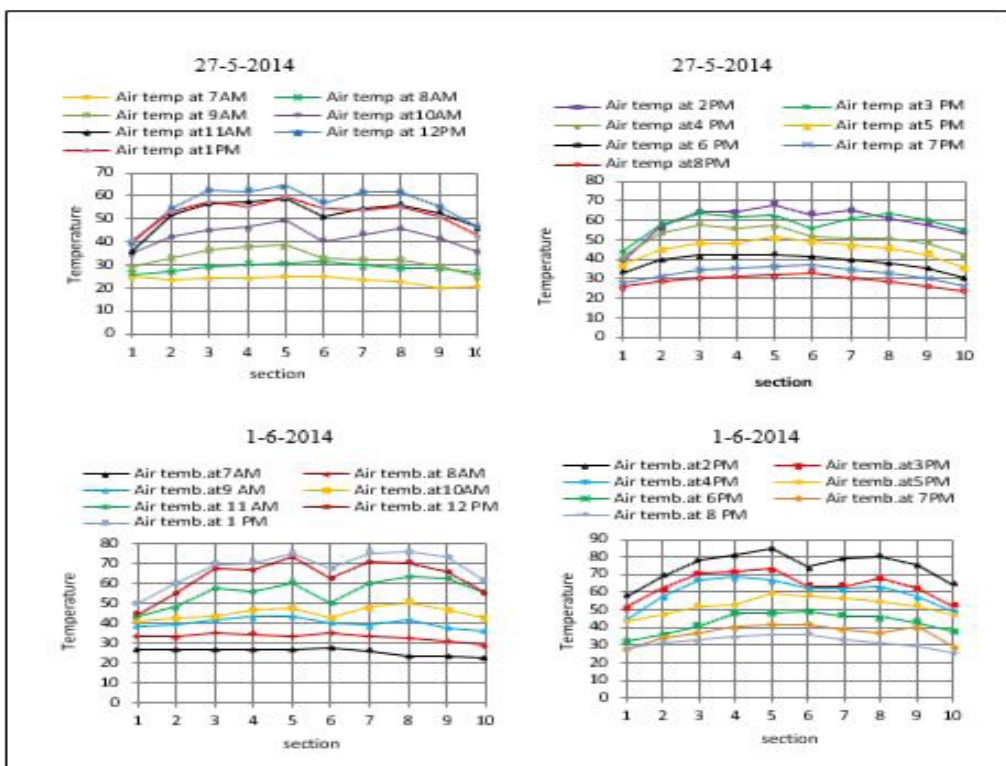

Figure (13): Air temperature distribution inside the collector at different sections and times (experimental results with water containers as thermal storage) 


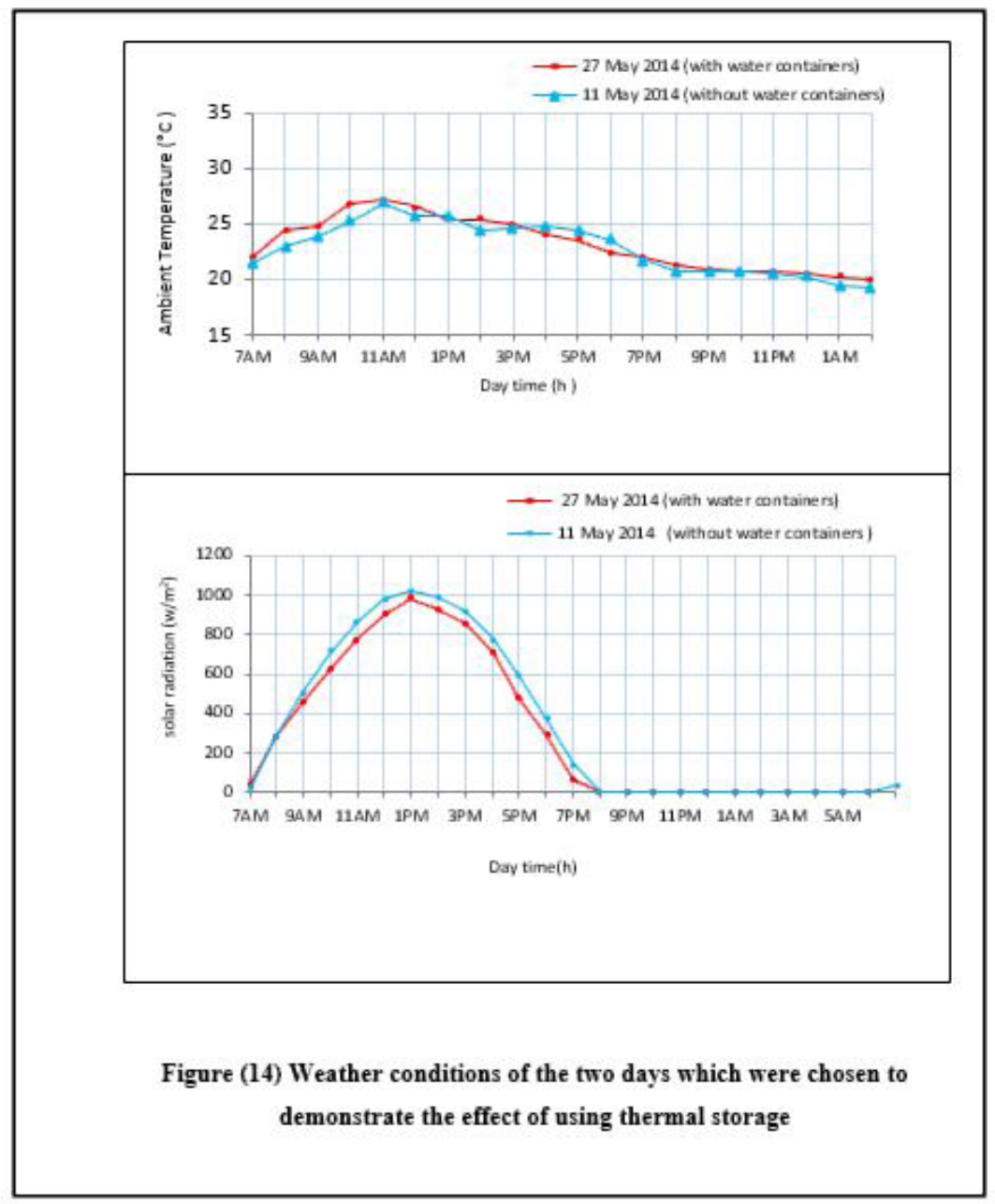

the thermal energy storage in the solar collector has been looked at as a method for re-shaping the power output profile and increasing the operation flexibility of a solar updraft tower.

\section{CONCLUSIONS}

From the experimental results and the tests that were carried out in this study, one can conclude the following; (1) From the tests considered in this study, the difference between air temperatures inside the collector and that of ambient reached about 45 ${ }^{\circ} \mathrm{C}$ and velocity about $3.6 \mathrm{~m} / \mathrm{s}$ on some days shortly after noon. (2) Despite the limited collector size and limited additional thermal storages used in the experiment, this study provides evidence that using of water (or any substance with high specific heat) as thermal storage improves the average air velocities through the solar chimney and gives the opportunity to operate the solar chimney longer after sunset. (3) The performance of solar chimney shortly after noon is higher than that in the morning and evening. (4) The air velocity at the chimney entrance is directly related to the temperature difference between collector internal temperature and the ambient temperature. (5) Temperature difference between the collector air outlet and the ambient can reach high values during summer time in Libya that enables to generate enough airflow through chimney for long time after sunset particularly when using 


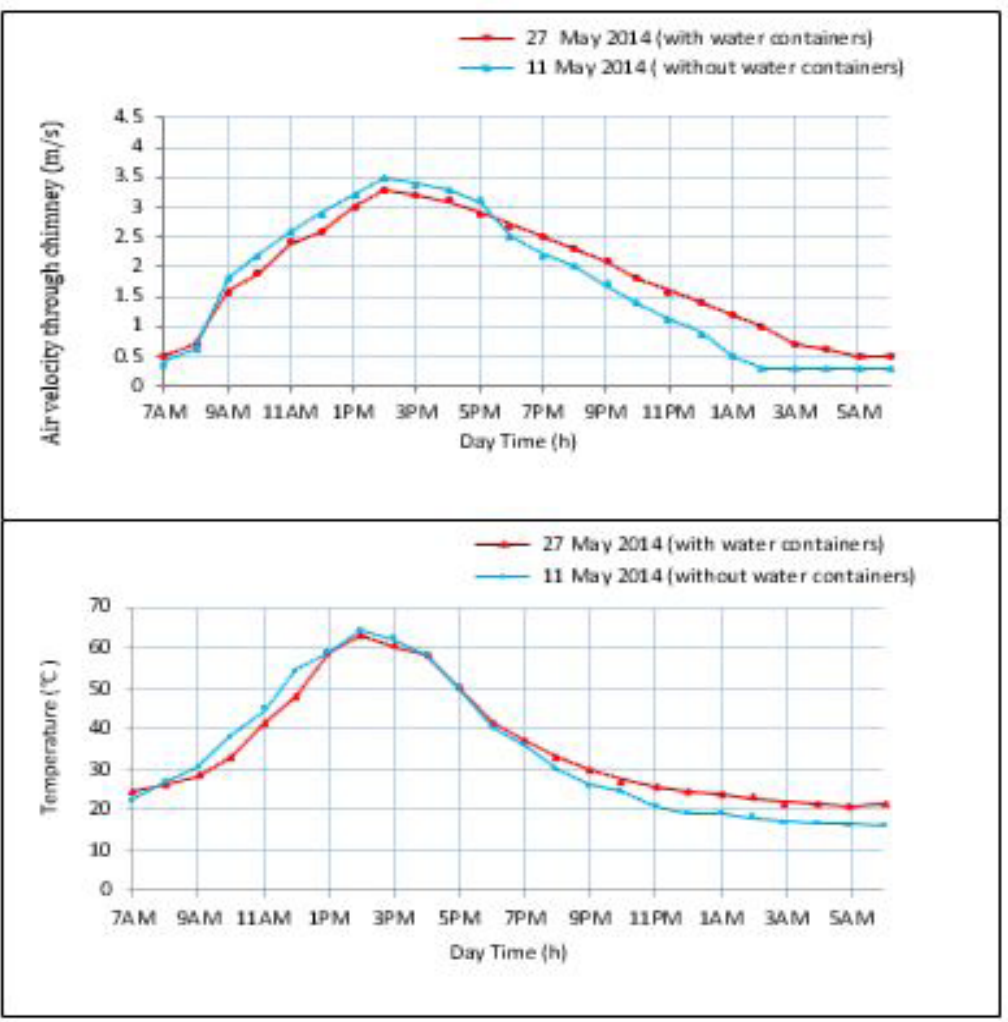

Figure (15) The Effect of using additional thermal storage on the behavior of the solar chimney system $\left(11^{\text {th }} \& 27^{\text {th }}\right.$ May 2014)

additional thermal storage like water container. (6) Wind speed outside the collector has a negligible effect on the solar chimney performance.

The present experiment should provide a good basis for understanding the effect of thermal storage on the performance of solar chimney system in order to arrive at a thorough understanding of the physical relationships and to evolve and identify points of approach for possible improvements. The future work should include the development of computer simulation code to describe the individual components, their performance, and their dynamic interaction.

\section{REFERENCES.}

[1]. Haaf W, Friedrich K, Mayr G, Schlaich J., "Solar chimneys- Part I: Principle and Construction of the Pilot Plant in Manzanares", International Journal of Solar Energy, 1983, pp. 3.

[2]. Haaf W., "Solar chimneys - Part II: Preliminary Test Results from the Manzanares Pilot Plant". International Journal of Solar Energy, pp.141161, 1984.

[3]. Schlaich, J. "The Solar Chimney: Electricity from the Sun”, Edition Axel Menges, Stuttgart, 1995.

[4]. Buğutekin A., "Experimental study of temperature 
field in a solar chimney plant in adiyaman", Journal of Thermal Science and Technology, (TIBTD-Turkey).pp. 1300-3615. 2012

[5]. Chaichan M. T. \& Kazem H. A “Thermal Storage Comparison for Variable Basement Kinds of a Solar Chimney Prototype in Baghdad - Iraq Weathers" International Journal of Applied Sciences (IJAS), Volume (2) : Issue (2) : 2011

[6]. Pretorius J. P., "Solar Tower Power Plant Performance" Thesis, Stellenbosch University of Stellenbosch, 2004.

[7]. Abuashe I. A "Performance study of solar chimney power plant under northwestern region of Libyan climate" Msc. Thesis, Subrata University
- Libya, 2013.

[8]. Pasumarthi N., Sherif S. A., "Experimental and theoretical performance of a demonstration solar chimney model - Part II: Experimental and theoretical results and economic analysis", International Journal of Energy Research, 22, 443-461, 1998.

[9]. Schlaich, J., Bergermann R., Schiel W., Weinrebe G. "Design of Commercial Solar Updraft Tower Systems-Utilization of Solar Induced Convective Flows for Power Generation". Journal of Solar Energy Engineering", Vol. 127, no 1, p. 117, 2005. 